\title{
ANÁLISE DA SECAGEM DE POLPA DE CUBIU EM LEITO DE JORRO A DIFERENTES TEMPERATURAS E TIPOS DE PARTÍCULAS INERTES
}

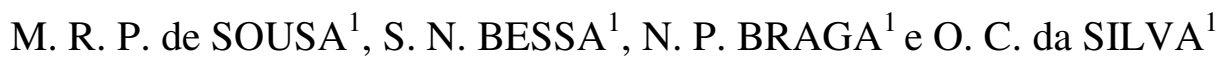 \\ ${ }^{1}$ Universidade Federal do Amazonas, Faculdade de Tecnologia, Departamento de Engenharia \\ Química \\ E-mail para contato: marcos.ruberson@gmail.com
}

\begin{abstract}
RESUMO - O cubiu (Solanum sessiliflorum Dunal) é espécie da região Amazônica que se destaca não só pelas boas propriedades nutritivas como pela presença de compostos bioativos, tendo sido empregado pelas populações nativas como auxílio no combate ao colesterol e ao diabetes. Uma alternativa de processamento do fruto a ser considerada, para difusão de seu consumo, é a desidratação, ou secagem, sendo a operação em leito de jorro com partículas inertes uma técnica bastante utilizada, que gera produtos de qualidade, com baixo teor de umidade. Todavia, para garantir boa eficiência, um grande número de variáveis deve ser estudado. Neste contexto, o presente trabalho teve como objetivo analisar o processo de secagem da polpa de cubiu a diferentes temperaturas e tipos de partículas inertes. Foram feitos testes a $60^{\circ} \mathrm{C}, 65^{\circ} \mathrm{C}$ e $70^{\circ} \mathrm{C}$, empregando como materiais das partículas inertes polietileno de alta densidade e vidro. Com os resultados, foi feita análise de variância para determinação da influência dos fatores sobre o rendimento de produção de pó. Foi possível determinar, então, que o tipo de partícula inerte empregado apresenta influência muito mais significativa que a temperatura, de modo que o uso de partículas de vidro como recheio propiciou o alcance de altos rendimentos na secagem de polpa sem aditivos.
\end{abstract}

\section{INTRODUÇÃO}

O cubiu (Solanum sessiliflorum Dunal) é uma hortaliça nativa da região amazônica, descoberta e domesticada pelas populações nativas. Entre suas características nutritivas estão o alto teor de fibras, proteínas, vitaminas e sais minerais sendo utilizado como medicamento para controle do diabetes, ácido úrico, colesterol, queimaduras e doenças cutâneas. Apesar de suas propriedades e sabor agradável, o cubiu trata-se, entretanto, de uma espécie que ainda possui mercado limitado, que necessita de estudos que apontem para novas formas de aproveitamento (SILVA FILHO et. al., 2005).

Neste contexto, entre as técnicas mais empregadas de processamento de frutas estão: a liofilização, secagem por atomização, a micro-ondas e a secagem em leito de jorro com partículas inertes. Esta última apresenta como vantagem, em comparação às demais técnicas, fornecer produtos de alta qualidade, todavia a um custo reduzido (SOUZA, 2009).

$\mathrm{Na}$ secagem de polpa em leito de jorro, um leito parcialmente preenchido com partículas inertes é submetido a secagem por convecção, contínua, em regime fluidodinâmico de jorro. A 


\section{Congresso Brasileiro de Engenharia Química \\ em Iniciação Científica \\ UFSCar - São Carlos - SP \\ 16 a 19 de Julho de 2017}

CONGRESSO BRASILEIRO DE ENGENHARIA

polpa é alimentada no leito de forma contínua ou intermitente de modo a recobrir as partículas de modo uniforme, formando um filme que é seco progressivamente. Esta película, com a redução da umidade torna-se quebradiça até que o pó formado seja arrastado pelo ar que escoa pelo leito, sendo então separado do ar por um ciclone Lapple.

Neste processo, entretanto, faz-se necessária a realização de um ajuste adequado dos parâmetros que influenciam a operação, dentre os quais se podem destacar a temperatura do ar de secagem e a taxa de escoamento do fluido, este por sua vez, diretamente relacionado à fluidodinâmica propiciada pelo tipo de partícula inerte empregada (MEDEIROS, 2001). Desta maneira, o estudo desenvolvido teve como objetivo avaliar o impacto da temperatura e do tipo de partícula inerte utilizada sobre o rendimento da produção de pó na secagem de polpa de cubiu em leito de jorro.

\section{MATERIAIS E MÉTODOS}

\subsection{Aparato experimental}

O leito de jorro empregando para secagem de polpa de cubiu é constituído de estrutura cilíndrico-cônica, em aço inoxidável e visor lateral de acrílico. A base cônica tem ângulo de $45^{\circ}$, altura de $8 \mathrm{~cm}$ e diâmetro de entrada de $6 \mathrm{~cm}$. A parte cilíndrica tem diâmetro de $18 \mathrm{~cm}$ e $90 \mathrm{~cm}$ de altura. Para promover a separação do pó formado durante a secagem do ar, a parte superior do leito é conectada a um ciclone Lapple.

Além do leito, a unidade experimental é composta por um soprador de ar, um trocador de calor elétrico para aquecimento do ar de secagem e os seguintes equipamentos de medição: termohigrômetros dispostos na alimentação e na saída do leito, anemômetro e manômetro diferencial. Uma bomba peristáltica, conectada a um ponto na lateral do leito permite a alimentação da polpa a ser secada. $\mathrm{O}$ aparato de secagem é representado conforme a Figura 1.

Figura 1 - Esquema do equipamento de secagem em leito de jorro (SOUSA Jr., 2012).

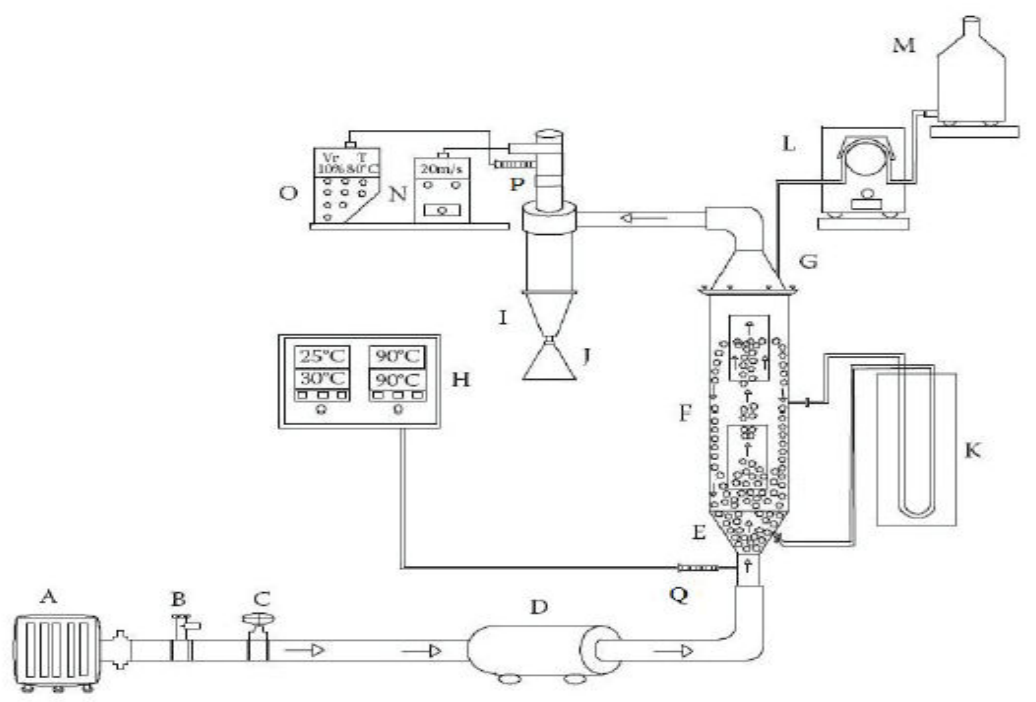

Legenda dos equipamentos

A - Soprador de ar

B - Válvula de escape

C - Válvula de passagem

D - Trocador de calor

E - Partículas inertes

F - Visor de acrilico

G - Ponto de alimentação do leito de jorro

$\mathrm{H}$ - Painel de controle

I - Ciclone

J - Recipiente colertor do pó

$\mathrm{K}$ - Manômetro diferencial

L - Bomba peristáltica

M - Recipiente de armazenamento da polpa

N - Anemômetro

- Termohigrômetro

P - Termopar

Q - Termômetro 


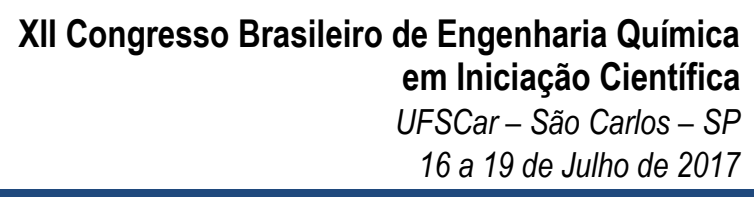

\subsection{Polpa e partículas inertes}

Nos ensaios de secagem, foi utilizada polpa de cubiu preparada a partir do despolpamento manual de frutos in natura, adquiridos em feiras livres. Fatias do fruto despolpado passaram por branqueamento em banho termostático com água, a temperatura constante de $90{ }^{\circ} \mathrm{C}$, durante cinco minutos e resfriamento com gelo. Estas foram então, trituradas em processador doméstico e batidas em liquidificador para obtenção de polpa homogênea. Quanto às partículas inertes, foram empregadas partículas de PEAD (polietilento de alta densidade) com diâmetro médio de $1,84 \pm 0,05 \mathrm{~mm}$ e massa específica de $935,3 \pm 0,5 \mathrm{~kg} / \mathrm{m}^{3}$, e partículas de vidro com diâmetro médio de $2,00 \pm 0,05 \mathrm{~mm}$ e massa específica de aproximadamente $2500 \pm 0,5 \mathrm{~kg} / \mathrm{m}^{3}$.

\subsection{Procedimento experimental}

Foram feitos ensaios de secagem a três níveis de temperaturas de ar de secagem $\left(60^{\circ} \mathrm{C}, 65^{\circ} \mathrm{C}\right.$ e $70^{\circ} \mathrm{C}$ ) para cada tipo de partícula inerte, tendo os ensaios sido realizados em duplicata. A vazão do ar de secagem foi especificada em, aproximadamente, 1,3 vezes a vazão mínima de jorro. Assim, foram feitos, ao todo, 12 experimentos.

Em cada ensaio foram colocados, aproximadamente, $3 \mathrm{~kg}$ de partículas inertes no leito. Após isto, o sistema de medição e aquisição de dados foi ligado e então, acionado o soprador, ajustandose a vazão de ar por meio da válvula de passagem e a temperatura do ar de secagem pelo controlador do trocador de calor, conforme a configuração de cada experimento. Após isto, aguardou-se um tempo de aproximadamente 30 minutos para estabilização da temperatura no sistema e uma amostra previamente preparada de em torno de $150 \mathrm{~g}$ de polpa foi alimentada no leito através de bomba peristáltica.

A alimentação da polpa foi contínua a vazão de $10 \mathrm{~g} / \mathrm{min}$. O pó formado ao longo do experimento foi coletado em recipiente de vidro acoplado ao ciclone Lapple, tendo sido mantido acondicionado livre de contato com o ar e posteriormente, pesado em balança semianalítica para aferição da quantidade de pó produzida. O teor de umidade da polpa foi medido, bem como do pó obtido, através de analisador de umidade eletrônico. Assim, foi determinado o rendimento mássico de produção de pó conforme a Equação 1.

$$
\eta_{p o ́}=\frac{m_{p o} \square\left(1-X_{p o}\right) \square 100}{m_{p o l p a} \square\left(1-X_{p o l p a}\right)}
$$

\section{RESULTADOS E DISCUSSÃO}

Os resultados obtidos para secagem de polpa de cubiu em leito de jorro, variando a temperatura e o tipo de partícula inerte, são apresentados, contendo como respostas a umidade do pó e o rendimento mássico, na Tabela 1. A umidade da polpa, medida anteriormente aos experimentos, foi de 93,41 \%b.u., e quanto à umidade do pó para os ensaios com partículas de vidro, situaram-se em valores inferiores a $0,5 \%$ b.u., não sendo possível a medição pelo equipamento abaixo desta faixa. Assim, este valor foi estendido, como estimativa, aos demais experimentos com partículas de vidro para determinação do rendimento. 


\section{Congresso Brasileiro de Engenharia Química \\ em Iniciação Científica \\ UFSCar - São Carlos - SP \\ 16 a 19 de Julho de 2017}

Tabela 1 - Resultados para secagem de polpa de cubiu em leito de jorro.

\begin{tabular}{|c|c|c|c|c|c|c|c|c|c|}
\hline \multirow{3}{*}{$\begin{array}{c}\text { Tipo de } \\
\text { partículas } \\
\text { inertes }\end{array}$} & \multicolumn{9}{|c|}{ Temperatura } \\
\hline & \multicolumn{3}{|c|}{60} & \multicolumn{3}{|c|}{65} & \multicolumn{3}{|c|}{70} \\
\hline & mpó (g) & $\begin{array}{c}\text { Xpó } \\
\text { (\%b.u.) }\end{array}$ & $\eta(\%)$ & mpó (g) & $\begin{array}{c}\text { Xpó } \\
\text { (\%b.u.) }\end{array}$ & $\eta(\%)$ & mpó (g) & $\begin{array}{c}\text { Xpó } \\
\text { (\%b.u.) }\end{array}$ & $\eta(\%)$ \\
\hline \multirow{2}{*}{ PEAD } & 0,699 & 3,1 & 6,76 & 0,905 & 8,6 & 9,45 & 0,871 & 1,9 & 9,38 \\
\hline & 0,995 & 2,9 & 9,52 & 1,521 & 12,2 & 13,36 & 1,086 & 1,9 & 10,95 \\
\hline \multirow{2}{*}{ Vidro } & 5,930 & 0,5 & 59,36 & 5,999 & - & 61,97 & 7,401 & - & 76,13 \\
\hline & 4,846 & - & 49,48 & 5,980 & - & 59,02 & 6,867 & - & 70,46 \\
\hline
\end{tabular}

Como é possível observar, o rendimento de produção do pó de cubiu ao longo dos experimentos variou de $6,76 \%$ a $76,13 \%$ e a umidade do pó oscilou entre $0,5 \%$ b.u e 12,2 \%b.u.. A partir destes dados, foi desenvolvida análise de variância, com auxílio do Microsoft Office Excel $2010 \circledast$, para estudo da influência das variáveis de entrada, temperatura do ar de secagem e tipo de partículas inertes, sobre o rendimento. A tabela ANOVA produzida pelo programa é apresentada conforme a Tabela 2 seguinte.

Tabela 2 - Tabela ANOVA para os resultados da secagem de polpa de cubiu em leito de jorro.

\begin{tabular}{|c|c|c|c|c|c|c|}
\hline Fonte da variação & $\begin{array}{l}\text { Soma dos } \\
\text { quadrados }\end{array}$ & $\begin{array}{l}\text { Graus de } \\
\text { liberdade }\end{array}$ & $\begin{array}{c}\text { Média } \\
\text { dos } \\
\text { quadrados }\end{array}$ & Fcalc & Valor $\mathrm{p}$ & Ftab \\
\hline $\begin{array}{c}\text { Tipo de partículas } \\
\text { inertes }\end{array}$ & 8442,4 & 3 & 2814,1 & 95,643 & 0,000 & 4,757 \\
\hline Temperatura & 219,2 & 2 & 109,6 & 3,725 & 0,089 & 5,143 \\
\hline Erro & 176,5 & 6 & 29,4 & & & \\
\hline Total & 8838,208 & 11 & & & & \\
\hline
\end{tabular}

A partir da tabela ANOVA, observa-se que o tipo de partículas inertes foi o parâmetro de maior influência sobre a resposta, apresentando valor aproximadamente nulo de vapor p. Quanto à temperatura do ar de secagem, pode-se afirmar que apresenta, estatisticamente, significância marginal. Isto é, embora o valor p não seja menor que 0,05 , o limite para significância estatística quando assumida margem de confiança de $95 \%$, para distribuição normal, este se mostra inferior a $10 \%$, indicando a possibilidade de esta variável ser influente no processo (MONTGOMERY, 2001).

Comparativamente a outros estudos correlatos, de secagem de pastas e polpas em leito de jorro, como de açaí e graviola, a temperatura não se apresenta como fator influente (COSTA et. al., 2013; MACHADO et. al., 2015). Isto se deve ao fato de, na operação a análise ter sido combinada com a variação do tipo de partículas inertes. Tal fator apresenta impacto determinante sobre a fluidodinâmica do leito, o que pode ser observado desde a diferença relativamente alta entre a massa específica entre os materiais.

As partículas de vidro apresentam massa específica muito maior, e por esta razão, a vazão mínima de jorro requerida é consideravelmente maior em comparação com o uso de partículas de PEAD como recheio. Desta forma, a vazão de ar é incrementada de forma significativa ao se 
empregar partículas de vidro.

A vazão de ar, por sua vez, apresenta influência ainda mais intensa que a temperatura do ar de secagem sobre a produção de pó. Isto porque, vazões de ar mais elevadas promovem maior circulação de sólidos e choque de partículas, o que favorece a quebra da película de sólidos formada e assim, a produção de pó, além de impedir com mais eficácia, a aderência de material às paredes do equipamento (MACHADO et. al., 2015). Observou-se ainda, experimentalmente, que o tempo de residência dos sólidos no leito foi consideravelmente menor, um indicativo de que a taxa de secagem foi aumentada.

$\mathrm{O}$ teste $\mathrm{F}$ também corrobora o fato de que a temperatura, em análise combinada com o tipo de inertes, não teve significância estatística quanto à sua influência sobre a resposta. Por outro lado, nota-se que, para o tipo de partículas inertes Fcalc apresentou valor de 95,643, muito maior que Ftab de 4,757, indicando que este fator é fortemente influente sobre o rendimento do processo. Uma vez que as partículas de vidro demandam, para regime fluidodinâmico de jorro, maiores vazões de ar, então os processos de transferência de calor e massa por convecção, naturalmente mais intensos, foram ainda mais favorecidos, aumentando de consideravelmente o rendimento da secagem (COSTA et. al., 2013).

\section{CONCLUSÃO}

Os testes de secagem de polpa de cubiu apontaram que o tipo de partícula inerte empregada no leito de jorro apresenta maior influência que a temperatura no rendimento da produção de pó, de modo que o uso de partículas de vidro propiciaram rendimentos consideravelmente maiores. A análise de variância apontou que o efeito deste fator foi muito mais significativo, o que é explicado pela mudança de material que constitui o recheio alterar a fluidodinâmica do leito. Os resultados mostram que o uso de partículas de vidro em leito de jorro para secagem da polpa de cubiu é uma alternativa viável, considerando o alto rendimento propiciado a temperaturas relativamente baixas e a ausência de quaisquer aditivos à polpa, embora a otimização do processo demande análise detalhada, especialmente, das características químicas do pó formado.

\section{NOMENCLATURA}

$\begin{array}{ll}\text { ๆpó } & \text { Rendimento de produção de pó (\%) } \\ \text { mpó } & \text { Massa de pó (g) } \\ \text { mpolpa } & \text { Massa de polpa (g) } \\ \text { Xpó } & \text { Teor de umidade do pó (\%b.u.) } \\ \text { Xpolpa } & \text { Teor de umidade da polpa (\%b.u.) } \\ \text { Fcalc } & \text { Valor calculado de F } \\ \text { Ftab } & \text { Valor tabelado de F }\end{array}$

\section{REFERÊNCIAS}

COSTA, R.G., ANDEROLA K., SILVA, C.A.M., FARIA L.J.G., TARANTO O.P. Estudo da secagem de açaí (Euterpe oleracea Mart) em leito de jorro. Anais do XXXVI Congresso Brasileiro de Sistema Particulados; 20-23 de outubro de 2013; Maceió - AL. Maceió: Editora da UFAL, 2013. 
MACHADO, I.P., DELMIRO T.M., MACHADO, A.K.T.., MEDEIROS, M.F.D.. Secagem em leito de jorro da mistura graviola e leite. Avaliação dos efeitos das variáveis de operação sobre parâmetros de produção, taxa de secagem e eficiência térmica. Anais do XXXVII Congresso Brasileiro de Sistema Particulados; 18-21 de outubro de 2013; São Carlos - SP. São Carlos: Editora da UFSCar, 2013.

MEDEIROS, Maria de F.D. et al. Drying of pastes in spouted beds: influence of the paste composition on the material. In.: Simpósio Internacional de Secagem, 14, 2004, São Paulo. Anais do $14^{\text {ao }}$ Simpósio Internacional de Secagem. São Paulo, 2004.

MONTGOMERY, D. C. Design and analysis of experiments. John Wiley \& Sons, New York, 2001. 699p.

SILVA FILHO, D. F.; YUYAMA, L. K. O.; AGUIAR, J. P. L; OLIVEIRA, M. C.; MARTINS, L. H. P. Caracterização e Avaliação do Potencial Agronômico e Nutricional de Etnovariedades de Cubiu (Solanum sessiliflorum, Dunal) da Amazônia. Acta Amazonica, v.35, n. 4, p. 399-406, 2005.

SOUZA, J. S. Secagem de Mistura de Polpa de Frutas Tropicais em Leito de Jorro. 2009, 155f. Tese (Doutorado em Engenharia Química). Programa de Pós Graduação em Engenharia Química, Universidade Federal do Rio Grande do Norte, Natal/RN. 